\title{
Schisandrin B Enhances Cerebral Mitochondrial Antioxidant Status and Structural Integrity, and Protects against Cerebral Ischemia/Reperfusion Injury in Rats
}

\author{
Na Chen, Po Yee Chiu, and Kam Ming Ko* \\ Department of Biochemistry, The Hong Kong University of Science and Technology; Hong Kong S.A.R., China. \\ Received March 25, 2008; accepted April 21, 2008
}

\begin{abstract}
Schisandrin B (Sch B), a dibenzocyclooctadiene derivative isolated from the fruit of Schisandra chinensis, has been shown to enhance mitochondrial antioxidant status in liver, heart and brain tissues in rodents. Whether or not long-term Sch B treatment can protect against oxidative stress-induced cerebral damage remains unclear. In the present study, the effect of long-term Sch B treatment $(1-30 \mathrm{mg} / \mathrm{kg} / \mathrm{d} \times 15)$ on cerebral ischemia/reperfusion (I/R) injury was examined in rats. Sch $B$ treatment protected against $I / R$-induced cerebral damage, as evidenced by the significant increase in the percentage of 2,3,5-triphenyl tetrazolium chloride (TTC)-stained tissues in representative brain slices, when compared with the $S c h$ B-untreated and $I / R$ control. The cerebroprotection was associated with an enhancement in cerebral mitochondrial antioxidant status, as assessed by the level/activity of reduced glutathione, $\alpha$-tocopherol and Mn-superoxide dismutase, as well as the improvement/preservation of mitochondrial structural integrity, as assessed by the extents of malondialdehyde production, $\mathrm{Ca}^{2+} \mathrm{loading}$ and cytochrome $\mathrm{c}$ release, as well as the sensitivity to $\mathrm{Ca}^{2+}$-induced permeability transition, in control and I/Rchallenged rats. In conclusion, long-term Sch B treatment could enhance cerebral mitochondrial antioxidant status as well as improve mitochondrial structural integrity, thereby protecting against $I / R$ injury.
\end{abstract}

Key words schisandrin B; ischemia/reperfusion; mitochondria; permeability transition; antioxidant; brain

Schisandrin B (Sch B) is the most abundant, active dibenzocyclooctadiene derivative isolated from the fruit of Schisandra chinensis (FS), a traditional Chinese herb clinically used for the treatment of viral and chemical hepatitis. ${ }^{1)}$ A recent study from our laboratory has demonstrated that long-term treatment with Sch B was able to enhance mitochondrial antioxidant status and the resistance to $\mathrm{Ca}^{2+}$-induced mitochondrial permeability transition (PT) in an ageindependent manner in various rat organs including the heart and brain. ${ }^{2)}$ The Sch B-induced enhancement of mitochondrial protective parameters in the heart was associated with the protection against myocardial ischemia/reperfusion (I/R) injury in both young and middle-aged rats. ${ }^{2)}$ Given that the maintenance of mitochondrial antioxidant status and structural integrity is crucial for cell survival, ${ }^{3)} \mathrm{Sch} \mathrm{B}$ has been proposed to be used as a universal cell protectant against tissue damage caused by endogenous and exogenous oxidants. ${ }^{2)}$ While the protection of Sch B against I/R injury has been demonstrated in the heart, ${ }^{2,4)}$ it is still unclear whether Sch B treatment can produce any beneficial effect on cerebral $\mathrm{I} / \mathrm{R}$ injury.

In the present study, we investigated the effect of longterm treatment with Sch B on cerebral I/R injury in rats. To elucidate the biochemical mechanism involved in the cerebroprotection against I/R injury, cerebral mitochondrial antioxidant status as well as mitochondrial structural integrity were assessed in control and Sch B-treated rats, without or with $\mathrm{I} / \mathrm{R}$ challenge.

\section{MATERIALS AND METHODS}

Chemicals Reduced glutathione (GSH), oxidized glutathione, glutathione reductase, cytochrome c, $\alpha$-tocopherol $(\alpha$-TOC), cyclosporin A (Cs A) and 2,3,5-triphenyl tetrazolium chloride (TTC) were purchased from Sigma Chemi- cal Co. (St. Louis, MO, U.S.A.). All other chemicals were of analytical grade. Solvents used for HPLC were of HPLC grade.

Herbal Material Dried FS was imported from mainland China. It was authenticated and supplied by a commercial dealer (Lee Hoong Kee Ltd.) in Hong Kong. Sch B was purified from the petroleum ether extract of FS, with the purity being higher than $95 \%$ as determined by HPLC analysis. ${ }^{5}$

Animal Care Adult female Sprague-Dawley rats (8-10 weeks; $200-250 \mathrm{~g}$ ) were maintained under a 12-h dark/light cycle at about $22^{\circ} \mathrm{C}$, and allowed food and water ad libitum. Experimental protocols were approved by the Research Practice Committee at the Hong Kong University of Science \& Technology.

Drug Treatment Animals were randomly divided into groups, with five animals in each. In the Sch B treatment groups, rats were intragastrically administered with Sch B (dissolved/suspended in olive oil) at a daily dose of 1,10 or $30 \mathrm{mg} / \mathrm{kg}$ from day 1 to day 15 of the experiment. This dosage regimen was found to be effective in protecting against myocardial ischemia/reperfusion injury in rats. ${ }^{2)} \mathrm{Sch}$ B-untreated animals received the vehicle (i.e. olive oil) only. The rat model of cerebral I/R injury was modified from that of Ischikawa and Konishi. ${ }^{6}$ Phenobarbital-anesthetized rats $(100 \mathrm{mg} / \mathrm{kg}$, i.v.) were subjected to $120 \mathrm{~min}$ of ischemia by occlusion (using aneurysm clips) of both left and right common carotid arteries, which were exposed through a middle skin incision. At the end of the ischemic period, the carotid arteries were declamped and blood reperfusion was permitted for $60 \mathrm{~min}$. Non-I/R animals were sham operated. After the $\mathrm{I} / \mathrm{R}$ experiment, the brain was removed and frozen for $10 \mathrm{~min}$ at $-20^{\circ} \mathrm{C}$, and then fitted into a mould. Six coronal brain sections $(6-8 \mathrm{~mm}$ thick) were sliced from the front pole using a razor. The sections were incubated in phosphatebuffered saline containing $2 \%(\mathrm{w} / \mathrm{v})$ TTC at $37^{\circ} \mathrm{C}$ for 
$10 \mathrm{~min}$, and then kept in $10 \%(\mathrm{v} / \mathrm{v})$ buffered formalin $(\mathrm{pH}$ 7.0) overnight. The percentage of TTC-stained (i.e., viable) tissue with respect to the whole piece of tissue was measured by ImageJ software (NIH, U.S.A.). The extent of I/R injury was assessed by noting the difference between the non-I/R and I/R animals in the percentage of TTC-stained tissue in the fourth brain slice from the pole. In a parallel set of experiments, whole brains were harvested and subjected to biochemical analysis.

Preparation of Tissue Homogenate and Mitochondrial Fraction Minced whole brain tissues (ca. $2 \mathrm{~g}$ ) were homogenized in $10 \mathrm{ml}$ of ice-cold sucrose buffer $(0.25 \mathrm{M}$ sucrose, $0.1 \mathrm{~mm} \mathrm{Na} \mathrm{NDDTA}_{2} 5 \mathrm{~mm}$ Tris/HCl, pH 7.4), which was supplemented with a cocktail of protease inhibitors $(0.2 \mathrm{mg} / \mathrm{ml}$ soybean trypsin inhibitor, $0.2 \mathrm{mg} / \mathrm{ml}$ bacitracin, $0.16 \mathrm{mg} / \mathrm{ml}$ benzamidine), using a Teflon-glass homogenizer at $200 \mathrm{rpm}$ for 8-10 complete strokes. Mitochondrial pellets were prepared from tissue homogenates by centrifugation at $800 \times \boldsymbol{g}$ at $4{ }^{\circ} \mathrm{C}$ for $30 \mathrm{~min}$, as described. ${ }^{7)}$ Mitochondrial pellets were then resuspended in $1 \mathrm{ml}$ of homogenizing buffer and constituted the mitochondrial fraction. The protein concentration of mitochondrial fractions was determined using a Bio-Rad protein assay kit.

Mitochondrial Antioxidant Status Mitochondrial antioxidant status was assessed by measuring the levels of GSH and $\alpha$-TOC as well as the activity of Mn-SOD, as previously described. $^{7,8)}$ In brief, aliquots $(200 \mu \mathrm{l})$ of mitochondrial fractions were used for measuring mitochondrial GSH and $\alpha$ TOC levels by an enzymatic method and HPLC method, respectively, using GSH and $\alpha$-TOC as standards. The MnSOD activity was measured by monitoring the oxidation of cytochrome c caused by superoxide radicals generated from the xanthine oxidase/xanthine reaction.

Mitochondrial Structural Integrity Mitochondrial structural integrity was assessed by measuring the extents of mitochondrial malondialdehdye (MDA) production, cytochrome c release and calcium loading, as well as the sensitivity of mitochondria to $\mathrm{Ca}^{2+}$-induced PT, as previously described.9) In brief, mitochondrial MDA level was measured by a HPLC method. Cytosolic cytochrome c level, as indirect measure of mitochondrial cytochrome c release, was estimated by Western blot analysis using specific antibodies to cytochrome c (clone 7H8.2C12, BD PharMingen, San Diego, CA, U.S.A.) following SDS-PAGE of cytosolic fractions, using a separating gel with $15 \%(\mathrm{w} / \mathrm{v})$ acrylamide. The extent of mitochondrial contamination of cytosolic fractions, which was found to be negligible, was determined using specific antibodies against complex IV. The immunoblots were visualized using the enhanced chemiluminescence reaction (Amersham ECL +, Piscataway, NJ, U.S.A.), and analyzed by densitometry (BioRad, Hercules, CA, U.S.A.). The amounts (arbitrary units) of cytochrome c were normalized with reference to actin levels (arbitrary units) in the sample. The $\mathrm{Ca}^{2+}$ content was measured using a $\mathrm{Ca}^{2+}$-sensitive fluorescence probe, Fluo-5N AM ester, and a Victor $^{2} \mathrm{~V}$ multi-Label counter. The $\mathrm{Ca}^{2+}$ dissociation constant $\left(K_{\mathrm{d}}\right)$ was determined by using a $\mathrm{Ca}^{2+}$ calibration kit in the concentration range 1 $1000 \mu \mathrm{M}$, and the $K_{\mathrm{d}}$ value was estimated to be $c a .98 \mu \mathrm{M}$, in good agreement with data provided by the manufacturer. An aliquot $(25 \mu \mathrm{l})$ of a mitochondrial fraction $(0.5 \mathrm{mg} / \mathrm{ml}$ final concentration) was mixed with $25 \mu \mathrm{l}$ of incubation buffer
(100 mM KCl, $30 \mathrm{~mm}$ MOPS, pH 7.2) in a 96-well black microtiter plate. The mixture was incubated at $25^{\circ} \mathrm{C}$ for $15 \mathrm{~min}$ and $25 \mu \mathrm{l}$ digitonin $(50 \mu \mathrm{g} / \mathrm{ml})$, with $25 \mu \mathrm{l}$ Fluo-5N AM ester ( $1 \mu \mathrm{M}$ in $0.005 \%$ Pluronic F-127), was then added. The reaction mixture was incubated at $25^{\circ} \mathrm{C}$ for $30 \mathrm{~min}$, and the fluorescence reading was measured at an excitation wavelength of $488 \mathrm{~nm}$ and an emission wavelength of $532 \mathrm{~nm}$. The mitochondrial $\mathrm{Ca}^{2+}$ content was estimated from a standard calibration curve and expressed in $\mu \mathrm{mol} / \mathrm{mg}$ protein. The measurement of the sensitivity of mitochondria to $\mathrm{Ca}^{2+}$-induced PT was performed as follows. An aliquot $(1.6 \mathrm{ml})$ of a mitochondrial sample $(0.5 \mathrm{mg}$ protein $/ \mathrm{ml})$ was prepared by mixing the mitochondrial fraction with incubation buffer containing $125 \mathrm{~mm}$ sucrose, $65 \mathrm{~mm} \mathrm{KCl,} 10 \mathrm{~mm}$ Hepes (pH 7.2), $5 \mathrm{~mm}$ succinate (freshly prepared) and $5 \mu \mathrm{m}$ rotenone (freshly prepared). Aliquots $(200 \mu \mathrm{l})$ of the mitochondrial sample were mixed with $10 \mu \mathrm{l}$ of Cs A $(5 \mu \mathrm{M}$ in $0.5 \%$ ethanol; final concentration) or incubation buffer. The mixture was incubated at $30^{\circ} \mathrm{C}$ for $5 \mathrm{~min}$. An aliquot $(10 \mu \mathrm{l})$ of calcium chloride $\left(\mathrm{Ca}^{2+}\right)$ solution $(1 \mu \mathrm{M}$ final concentration) was then added, and the mixture was incubated at $30^{\circ} \mathrm{C}$ for $5 \mathrm{~min}$. Aliquots $(180 \mu \mathrm{l})$ of each mixture were pipetted to a 96 -well microtiter plate, and the initial absorbances of the mixtures at $520 \mathrm{~nm}$ were monitored for $5 \mathrm{~min}$ at $30^{\circ} \mathrm{C}$. The swelling reaction was then commenced by adding $20 \mu \mathrm{l}$ of $\mathrm{K}_{3} \mathrm{PO}_{4}$ $(0.5 \mathrm{~mm}, \mathrm{pH} 7.2)$, and the absorbance at $520 \mathrm{~nm}$ of the reaction mixtures was read every $2 \mathrm{~min}$ for $30 \mathrm{~min}$ at $30^{\circ} \mathrm{C}$, using a Victor $\mathrm{V}^{2}$ Multi-Label Counter. The extent of mitochondrial swelling was estimated by computing the area under the curve $(A U C)$ of the declining graph plotting percentage initial absorbance $(100 \%$; baseline) against time ( $\mathrm{min})$, to obtain $A U C_{1}$. The extent of mitochondrial PT $\left(\triangle A U C_{1}\right)$ was estimated by subtracting the $A U C_{1}$ with $\mathrm{Cs}$ A from the $A U C_{1}$ without $\mathrm{Cs} \mathrm{A}$. The $\mathrm{Ca}^{2+}$-induced mitochondrial PT was expressed as the ratio of the $\triangle A U C_{1}$ induced by both $\mathrm{Ca}^{2+}$ and $\mathrm{PO}_{4}^{3-}$ to that induced by $\mathrm{PO}_{4}^{3-}$ only (i.e., we obtained a $\mathrm{Ca}^{2+}$ induced mitochondrial swelling index).

Statistical Analysis Data were analyzed by one-way Analysis of Variance (ANOVA). Post hoc multiple comparisons were done with LSD. $p$-values $<0.05$ were regarded as statistically significant.

\section{RESULTS}

Long-term Sch B treatment did not produce any detectable effect on the viability of brain tissue, as assessed by measuring the percentage of TTC-stained tissue in the fourth brain slice (Fig. 1). I/R challenge caused a significant decrease $(24 \%)$ in the percentage of TTC-stained tissue, an indication of brain infarction. Long-term Sch B pretreatment protected against I/R-induced brain infarction, as evidenced by a dosedependent increase in the percentage of TTC-stained tissue, when compared with that of the Sch B untreated and I/R control, with the percent protection ranging from $10-33 \%$ (Fig. $1)$.

Sch B treatment enhanced the cerebral mitochondrial antioxidant status, as indicated by increases in the level/activity of GSH (13-35\%), $\alpha$-TOC (7-38\%) and Mn-SOD (14$28 \%$ ) in a dose-dependent manner (Table 1). In contrast, I/R challenge caused the impairment in cerebral mitochondrial antioxidant status, as evidenced by significant decreases in 
(a)

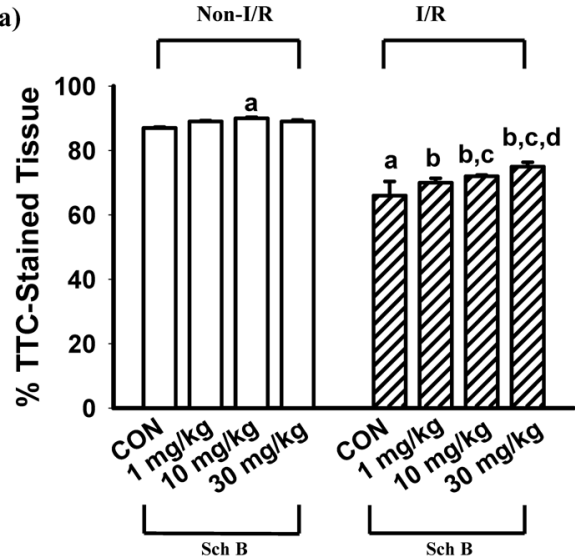

(b)

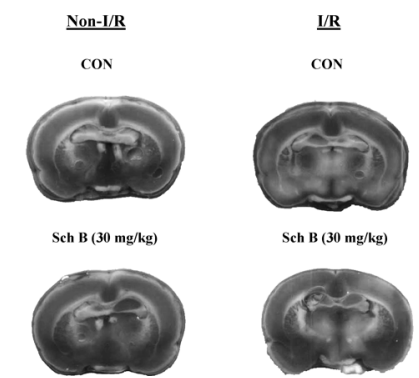

Fig. 1. Effect of Long-Term Sch B Treatment on Cerebral I/R-Injury in Rats

Animals were orally treated Sch B $(1-30 \mathrm{mg} / \mathrm{kg} / \mathrm{d})$ for $15 \mathrm{~d}$. Twenty-four hours after the last dosing with Sch B, animals were subjected to cerebral ischemia/reperfusion ( $\mathrm{I} / \mathrm{R}$ ) challenge, as described in Materials and Methods. The extent of $\mathrm{I} / \mathrm{R}$ injury was assessed by noting the difference between the Non-I/R and I/R groups in the percentages of TTC-stained tissue with respect to the whole tissue in representative brain slices. In the upper panel, values given are mean \pm S.E.M., with $n=5$. The lower panel shows representative TTC-stained brain slices in respective groups ${ }^{\text {a }}$ Significantly different from the Non-I/R control $(\mathrm{CON}) ;{ }^{\mathrm{b}}$ significantly different from the I/R CON; ${ }^{\mathrm{c}}$ significantly different from the respective $1 \mathrm{mg} / \mathrm{kg}$ Sch B group; ${ }^{\mathrm{d}}$ significantly different from the respective $10 \mathrm{mg} / \mathrm{kg}$ Sch B group.

the level/activity of GSH (15\%), $\alpha$-TOC (15\%) and Mn-SOD (14\%). The cerebroprotection afforded by Sch B pretreatment against I/R injury was associated with dose-dependent increases in the level/activity of mitochondrial GSH (5$24 \%), \alpha$-TOC $(9-21 \%)$ and Mn-SOD (9-24\%), when compared to the Sch B-untreated and I/R control.

Sch B treatment decreased the extents of cerebral mitochondrial MDA production (8-27\%), $\mathrm{Ca}^{2+}$ loading (5$17 \%)$ and cytochrome c release $(10-25 \%)$, as well as the susceptibility of mitochondria to $\mathrm{Ca}^{2+}$-induced PT $(9-19 \%)$ to varying extents (Figs. $2 \mathrm{a}-\mathrm{d}$ ), all of which are indirect measures of mitochondrial structural integrity. I/R challenge caused a disruption in cerebral mitochondrial structural integrity, as evidenced by significant increases in the extents of MDA production (45\%), $\mathrm{Ca}^{2+}$ loading (41\%) and cytochrome c release $(48 \%)$, as well as the sensitivity to $\mathrm{Ca}^{2+}$. induced PT $(16 \%)$, when compared to the Sch B-untreated and I/R control. Sch B pretreatment preserved the mitochondrial structural integrity in $\mathrm{I} / \mathrm{R}$ challenged rats, as indicated by significant and dose-dependent decreases in the values of mitochondrial parameters to varying extents $(7-23 \%)$, when compared to the Sch B-untreated and I/R control.
Table 1. Effect of Long-Term Sch B Treatment on Mitochondrial Antioxidant Status in Control and Ischemic-Reperfused Rat Brains

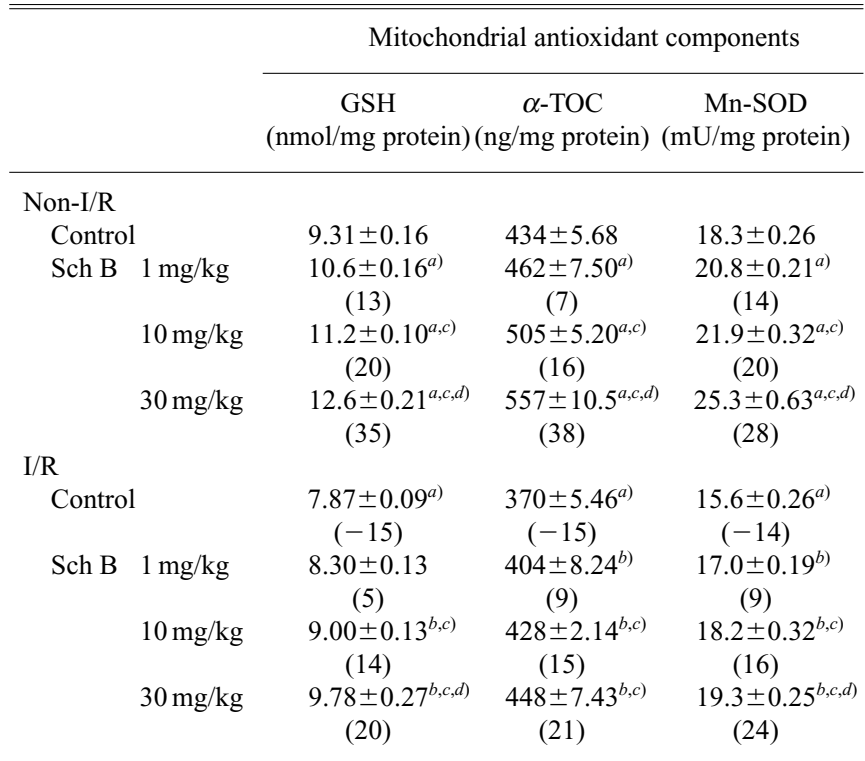

Animals were treated with Sch B and then received I/R challenge as described in Fig. 1. Cerebral mitochondrial reduced glutathione (GSH) and $\alpha$-tocopherol $(\alpha$-TOC) levels as well as Mn-superoxide dismutase (SOD) activity were measured. The number in parentheses is the percent change compared to the Non-I/R control. The italicized number in parentheses is the percent change compared to the $\mathrm{I} / \mathrm{R}$ control. Values given are mean \pm S.E.M., with $n=5$. a) Significantly different from the Non-I/R control; $b$ ) significantly different from the $\mathrm{I} / \mathrm{R}$ control; $c$ ) significantly different from the respective $1 \mathrm{mg} / \mathrm{kg}$ Sch B group; $d$ ) significantly different from the respective $10 \mathrm{mg} / \mathrm{kg}$ Sch B group.

\section{DISCUSSION}

It is well established that $\mathrm{I} / \mathrm{R}$ causes neuronal injury through multiple pathophysiological mechanisms, including intracellular calcium overload and reactive oxygen species (ROS) production, which eventually trigger necrotic and/or apoptotic cell death. ${ }^{10,11)}$ In the present study, long-term Sch $\mathrm{B}$ treatment was found to protect against cerebral I/R injury in a dose-dependent manner in young rats. It has been shown that the same Sch B treatment regimen also protected against myocardial I/R injury in both young and middle-aged rats. ${ }^{2)}$ In this regard, we also found that long-term Sch B treatment at a daily dose of $30 \mathrm{mg} / \mathrm{kg}$ for $15 \mathrm{~d}$ protected against cerebral I/R injury in 2-year old rats, with the degree of protection being larger than that of the young rats (unpublished data). Sch B may therefore be generally used as hormetic agent for preventing myocardial and cerebral $\mathrm{I} / \mathrm{R}$ injury occurring at both young and old ages.

Mitochondria are important source of ROS under both physiological $^{12)}$ and pathological conditions such as cerebral I/R injury. ${ }^{13)}$ The pathogenesis of cerebral I/R injury includes the opening of mitochondrial PT pores. ${ }^{14)}$ This is mediated by ROS and triggered by the increased mitochondrial $\mathrm{Ca}^{2+}$ levels. The enhancement of tissue/mitochondrial antioxidant capacity by overexpression of Mn-SOD, or by antioxidant supplementation, has been shown to protect against oxidative stress-induced tissue injury in the brain. ${ }^{15,16)}$ Consistent with this, our findings indicate that the cerebroprotection afforded by long-term Sch B treatment was associated with increases in the levels and activity of mitochondrial antioxidant components (GSH, $\alpha$-TOC, and Mn-SOD), as well as preservation of mitochondrial structural integrity. Structural integrity 


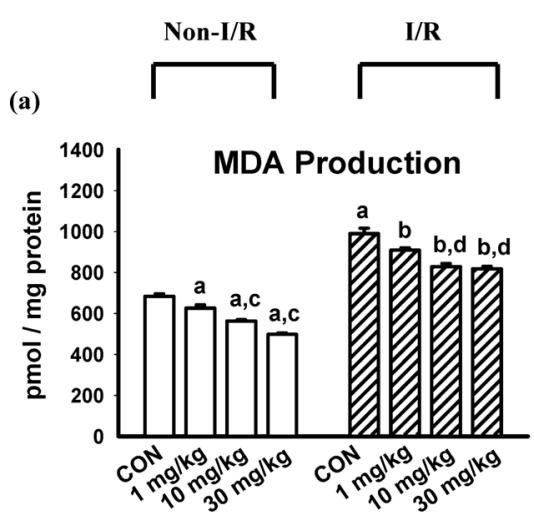

(b)

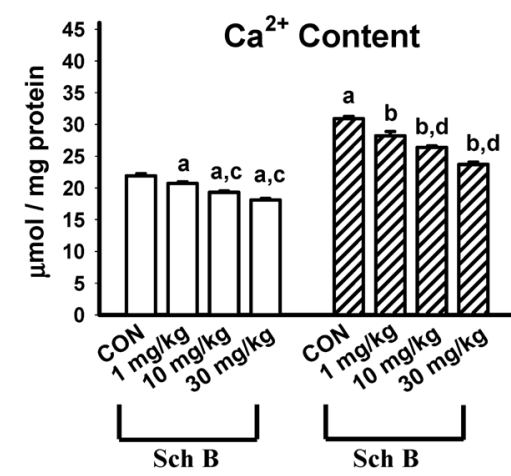

(c)

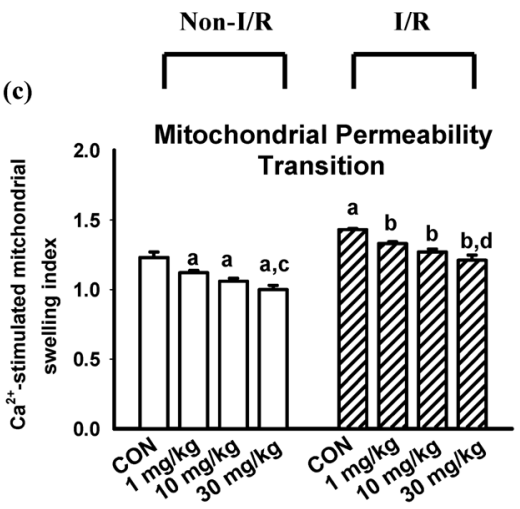

(d)

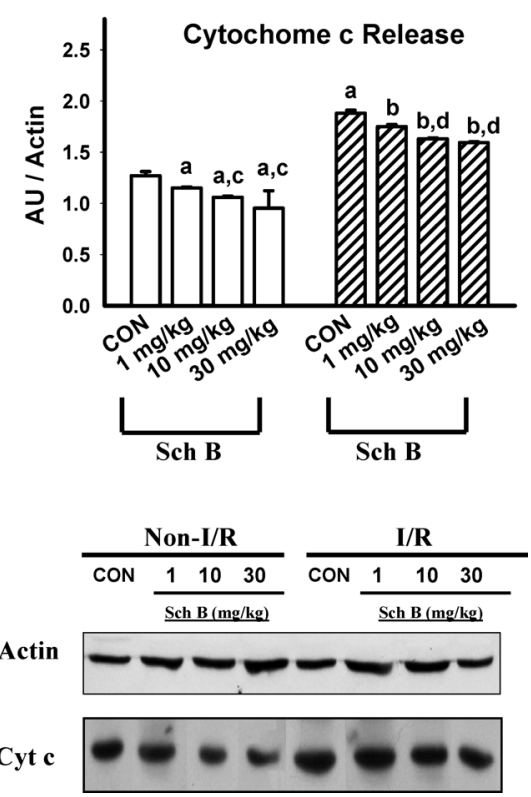

Fig. 2. Effects of Long-Term Sch B Treatment on Cerebral Mitochondrial Parameters in Control and I/R Challenge Rats

Animals were treated with Sch B and then challenged by I/R as described in Fig. 1. Mitochondrial fractions were prepared from cerebral tissues and then used for the measurement of malondialdehyde (MDA) production (a), $\mathrm{Ca}^{2+}$ content (b) and (c) $\mathrm{Ca}^{2+}$-induced permeability transition. Mitochondrial cytochrome $\mathrm{c}$ release was estimated by measuring the cytosolic cytochrome c level by Western blot analysis (d). The lower panel in (d) shows representative Western blots in various groups. Values given are mean \pm S.E.M., with

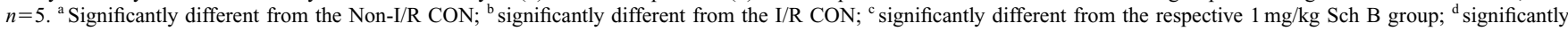
different from the respective $10 \mathrm{mg} / \mathrm{kg} \mathrm{Sch} \mathrm{B} \mathrm{group.}$

was assessed by measuring sensitivity to $\mathrm{Ca}^{2+}$-induced PT and by estimating MDA production levels, $\mathrm{Ca}^{2+}$ levels and cytochrome c release.

The opening of mitochondrial PT pores plays an important role in regulating necrotic and apoptotic cell death. ${ }^{17)}$ In the present study, I/R-induced damage in cerebral tissues was associated with an increased sensitivity of mitochondria to $\mathrm{Ca}^{2+}$-induced PT, as assessed by the measurement of mitochondrial swelling in vitro. Core components of the mitochondrial PT pore putatively include a voltage-dependent anion channel, an adenine nucleotide translocase (ANT), and a cyclophilin D displacing peptidyl-prolyl cis-trans isomerase (PPIase) activity. ${ }^{18)} \mathrm{Ca}^{2+}$ competes with ATP and activates PPIase, resulting in a conformational change converting the ANT complex to a non-specific pore. ${ }^{19)}$ While the loss of ion homeostasis resulting from ATP depletion following mitochondrial PT can lead to necrosis, ${ }^{20)} \mathrm{PT}$ also causes the leakage of cytochrome $\mathrm{c}$ from the mitochondria to the cytosol. $^{21)}$ The released cytochrome $\mathrm{c}$ can trigger a cascade of events that eventually leads to apoptosis. ${ }^{21,22)}$ The opening of mitochondrial PT pores, either in vivo or in vitro, is stimulated by high $\mathrm{Ca}^{2+}$ levels and by other stimuli, including increases in oxidants and depletion of adenine nucleotides. ${ }^{23)}$ Consistent with these observations, we found that mitochondria isolated for ischemic/reperfused cerebral tissues were more sensitive than control mitochondria to PT, had increased $\mathrm{Ca}^{2+}$ content, and were depleted in antioxidant components. These findings indicate increased (relative to control) oxidant production in these mitochondria. The disruption of mitochondrial structural integrity, as indicated by the increase in sensitivity to $\mathrm{Ca}^{2+}$-stimulated mitochondrial PT in vitro, was further evidenced by increases in the extents of mitochondrial MDA production, $\mathrm{Ca}^{2+}$ loading, and cytochrome c release. The cerebroprotection afforded by Sch B treatment was associated with the preservation of mitochondrial structural integrity, as evidenced by improvements in these parameters. In addition, the ATP generation capacity of cerebral mitochondria was also increased by long-term Sch B treatment in control and I/R conditions (data not shown).

Ongoing studies in our laboratory indicated that the an- 
tioxidant response triggered by Sch B was causally related to ROS arising from the cytochrome P-450-catalyzed metabolism of Sch B in both cultured hepatocytes and cardiomyocytes (unpublished data). Conceivably, Sch B is also metabolized in cerebral tissue and subsequently leads to the ROSmediated antioxidant response, with the resultant enhancement of mitochondrial antioxidant status. In addition, the enhanced antioxidant status may render the mitochondria less sensitive to $\mathrm{Ca}^{2+}$-induced PT, presumably by maintaining the reduced thiol status of the voltage-sensitive sites of the mitochondrial PT pore. ${ }^{24,25)}$

In conclusion, the results indicate that long-term Sch B treatment could enhance cerebral mitochondrial antioxidant status as well as improve mitochondrial structural integrity, thereby protecting against I/R injury.

\section{REFERENCES}

1) Ko R. K. M., Mak D. H. F., "Modern Herbal Medicine: Molecular Basis in Health \& Disease Management," ed. by Packer L., Halliwell B., Ong C. N., Marcel Dekker, New York, 2004, pp. 289-314.

2) Chiu P. Y., Leung H. Y., Poon M. K. T., Ko K. M., Biogerontology, 7, 199-210 (2006).

3) Pascoe G. A., Reed D. J., Free Radic. Biol. Med., 6, 209-224 (1989).

4) Chiu P. Y., Ko K. M., Biofactors, 19, 43-51 (2003).

5) Ip S. P., Poon M. K. T., Wu S. S., Che C. T., Ng K. H., Kong Y. C., Ko K. M., Planta Med., 61, 398- 401 (1995).

6) Ichikawa H., Konishi T., Biol. Pharm. Bull., 25, 898-903 (2002).

7) Chiu P. Y., Mak D. H. F., Poon M. K. T., Ko K. M., Planta Med., 68, 951-956 (2002).

8) Leung H. Y., Chiu P. Y., Poon M. K. T., Ko K. M., Rejuvenation Res.,
8, 238-247 (2005).

9) Chiu P. Y., Leung H. Y., Siu A. H. L., Chen N., Poon M. K. T., Ko K. M., Rejuvenation Res., 11, 43-62 (2008).

10) Traystman K. T., Kirsch J. R., Koehler R. C., J. Appl. Physiol., 71, 1185-1195 (1991).

11) Keller J. N., Kindy M. S., Holtsberg F. W., J. Neurosci., 18, 687-697 (1998).

12) Demin O. V., Kholodenko B. N., Skulakev V. P., Mol. Cell. Biochem., 184, 21-33 (1998).

13) Chan P. H., Ann. N.Y. Acad. Sci., 1042, 203-209 (2005).

14) Morin C., Simon N., Curr. Pharm. Des., 12, 739-757 (2006).

15) Callio J., Oury T. D., Chu C. T., J. Biol. Chem., 280, 18536-18542 (2005).

16) Navarro A., Gomez C., Sanchez-Pino M. J., Gonzalez H., Bandez M. J., Boveris A. D., Boveris A., Am. J. Physiol. Regul. Integr. Comp. Physiol., 289, R1392-R1399 (2005).

17) Lemasters J. J., Nieminen A. L., Qian T., Trost L. C., Elmore S. P., Nishimura Y., Crowe R. A., Cascio W. E., Bradham C. A., Brenner D. A., Herman B., Biochim. Biophys. Acta, 1366, 177-196 (1998).

18) Tsujimoto Y., Shimizu S., Apoptosis, 12, 835-840 (1995).

19) Galat A., Metcalfe S. M., Prog. Biophys. Mol. Biol., 63, 67-118 (1995).

20) Redegeld F. A., Moison R. M., Koster A. S., Noordhoek J., Eur. J. Pharmacol., 228, 229-236 (1992).

21) Green D. R., Reed J. C., Science, 281, 1309-1312 (1998).

22) Kang K. M., Haunstetter A., Aoki H., Usheva A., Izomo S., Circ. Res., 87, 118-125 (2000).

23) Brookes P. S., Yoon Y., Robotham J. L., Anders M. W., Sheu S. S., Am. J. Physiol. Cell Physiol., 287, C817-C833 (2004).

24) Costantini P., Petronilli V., Colonna R., Bernardi P., Toxicology, 99, 77-88 (1995).

25) Reed D. J., Savage M. K., Biochim. Biophys. Acta, 1271, 43-50 (1995). 